\title{
Design, development and deployment of a web-based interoperable registry for inherited retinal dystrophies in Portugal: the IRD-PT
}

João Pedro Marques ${ }^{1,2,3^{*}}$ (D) Ana Luísa Carvalho ${ }^{3,4,5}$, José Henriques ${ }^{6}$, Joaquim Neto Murta ${ }^{1,2,3}$, Jorge Saraiva ${ }^{3,4,7}$ and Rufino Silva $a^{1,2,3}$

\begin{abstract}
Background: The development of multicenter patient registries promotes the generation of scientific knowledge by using real-world data. A country-wide, web-based registry for inherited retinal dystrophies (IRDs) empowers patients and community organizations, while supporting formal partnerships research. We aim to describe the design, development and deployment of a country-wide, with investigators and stakeholders in the global aim to develop high-value, high-utility web-based, user-friendly and interoperable registry for IRDs—-the IRD-PT.

Results: The IRD-PT is a clinical/genetic research registry included in the retina.pt platform (https://www.retina.com. pt), which was developed by the Portuguese Retina Study Group. The retina.pt platform collects data on individuals diagnosed with retinal diseases, from several sites across Portugal, with over 1800 participants and over 30,000 consultations to date. The IRD-PT module interacts with the retina.pt core system which provides a range of basic functions for patient data management, while the IRD-PT module allows data capture for the specific purpose of IRDs. All IRDs are coded accordingly to the International Statistical Classification of Diseases and Related Health Problems (ICD) 9, ICD 10, ICD 11, and Orphanet Rare Disease Ontology (ORPHA codes) to make the IRD-PT interoperable with other IRD registries across the world. Furthermore, the genes are coded according to the Ontology of Genes and Genomes and Online Mendelian Inheritance in Man, whereas signs and symptoms are coded according to the Human Phenotype Ontology. The IRD-PT module pre-launched at Centro Hospitalar e Universitário de Coimbra, the largest reference center for IRDs in Portugal. As of April 1st 2020, finalized data from 537 participants were available for this preliminary analysis.
\end{abstract}

Conclusions: In the specific field of rare diseases, the use of registries increases research accessibility for individuals, while providing clinicians/investigators with a coherent data ecosystem necessary to boost research. Appropriate design and implementation of patient registries enables rapid decision making and ongoing data mining, ultimately leading to improved patient outcomes. We have described here the principles behind the design, development and deployment of a web-based, user-friendly and interoperable software tool aimed to generate important knowledge and collecting high-quality data on the epidemiology, genomic landscape and natural history of IRDs in Portugal.

\footnotetext{
*Correspondence: marquesjoaopedro@gmail.com

${ }^{1}$ Ophthalmology Unit, Centro de Responsabilidade Integrado em Oftalmologia (CRIO), Centro Hospitalar e Universitário de Coimbra (CHUC), Praceta Prof. Mota Pinto, 3000-075 Coimbra, Portugal

Full list of author information is available at the end of the article
}

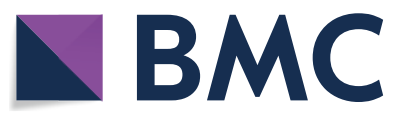

(c) The Author(s) 2020. Open Access This article is licensed under a Creative Commons Attribution 4.0 International License, which permits use, sharing, adaptation, distribution and reproduction in any medium or format, as long as you give appropriate credit to the original author(s) and the source, provide a link to the Creative Commons licence, and indicate if changes were made. The images or other third party material in this article are included in the article's Creative Commons licence, unless indicated otherwise in a credit line to the material. If material is not included in the article's Creative Commons licence and your intended use is not permitted by statutory regulation or exceeds the permitted use, you will need to obtain permission directly from the copyright holder. To view a copy of this licence, visit http://creativecommons.org/licenses/by/4.0/. The Creative Commons Public Domain Dedication waiver (http://creativeco mmons.org/publicdomain/zero/1.0/) applies to the data made available in this article, unless otherwise stated in a credit line to the data. 
Keywords: Inherited retinal dystrophies, Registry, Rare diseases, Interoperability, Software, Data management, Research, Epidemiology, Natural history, Clinical genetics

\section{Background}

The Agency for Healthcare Research and Quality defines a registry as "an organized system that uses observational study methods to collect uniform data (clinical and other) to evaluate specified outcomes for a population defined by a particular disease, condition, or exposure, and that serves one or more predetermined scientific, clinical, or policy purposes" [1]. Clinical registries have existed for decades in the field of ophthalmology [2-5], serving a variety of purposes, which include (1) capturing the epidemiologic features of an ocular disease or condition, (2) tracking outcomes and complications of drugs or procedures, (3) recording adverse events, or (4) combinations of the above [6]. In recent years, policy makers started recognizing clinical registries as an important tool for improving the value of healthcare. Outcome data is now used to fill in gaps of evidence that cannot be provided by randomized controlled trials [6]. Furthermore, data from clinical registries is also increasingly being used to facilitate learning networks and to establish research collaborations between scientific researchers, clinicians, industry, regulators, patient organizations, patients and families [7]. This is especially true for rare diseases where the small number of cases for each disease creates additional barriers in the translational research pathway, and makes identification and establishment of a substantial cohort a very difficult task.

Inherited retinal dystrophies (IRDs) are a clinically and genetically heterogenous group of diseases with an estimated prevalence of 1 in 3000 individuals [8]. Despite some common ground, genetic profiles vary considerably among regions and ethnic groups [9-16], thus highlighting the importance of obtaining reference population-based data. The presence of founder mutations may greatly contribute for these differences, as observed in a large Israeli population [9]. While local hospital-based registries may provide high quality information and resources, their coverage is usually small. To fully understand the prevalence and genomic landscape of IRDs, we must connect knowledge that is widespread throughout miscellaneous registries. The development of multicenter patient registries and natural history studies promote the generation of scientific knowledge by using real-world data. As rare diseases gain visibility as a public health priority and the marketplace expands, acknowledgement of the importance of building collaborative relationships in rare disease research increases [7]. A national, web-based registry for IRDs is able to empower patients and community organizations, while supporting formal partnerships with investigators and stakeholders in the global aim to develop high-value, high-utility research.

When developing a registry, it is essential to ensure that it is ethically governed, user-friendly and designed with maximum sustainability. This includes the implementation of foundational, structural, semantic, and organizational interoperability processes to optimize the utility of data and allow its linkage to other existing or future registries [7]. By making data computationally accessible, it is possible to bridge compatibility gaps between different hospitals, healthcare systems, registries and languages [17]. Adoption of comprehensive phenotype and rare disease ontologies enables this type of sharing by making data findable, accessible, interoperable, and reusable (FAIR principles) [18]. These features have made Orphanet Rare Disease Ontology (ORDO) a standard for rare disease coding in European health-care systems and led to the widespread adoption of ontologies like the Human Phenotype Ontology (HPO) by global genomics initiatives, like the European Reference Network for Rare Eye Disease (ERN-EYE) [17].

The purpose of this study is to describe the design, development and deployment of a country-wide, webbased, user-friendly and interoperable registry for IRDs-the IRD-PT.

\section{Results}

\section{Data capture}

The IRD-PT was designed to capture longitudinal data on IRDs. The data captured by the IRD-PT module is kept to a minimum to deliver an efficient and user-friendly data collecting tool. The user must complete all the mandatory fields/check all the mandatory boxes in order to save the entry. However, the system allows editing and/or completion of previously unanswered non-mandatory fields at the user's convenience. The list of covered clinical diagnoses is shown on Table 1, while the list of the genes and their respective Ontology of Genes and Genomes (OGG) and Mendelian Inheritance in Man (MIM) numbers are shown on Table 2. Even though inherited optic neuropathies and other genetically-associated retinal diseases (such as Pseudoxanthoma Elasticum-associated retinopathy or isolated foveal hypoplasia) are not IRDs per se, we opted to include them in the registry since these are common diagnoses in an Ophthalmic Genetics clinic. This is 
Table 1 List and ORPHA numbers of the clinical diagnoses covered by the IRD-PT module

\begin{tabular}{|c|c|c|}
\hline & $\begin{array}{l}\text { Inherited retinal dystrophies }{ }^{a} \\
\text { ORPHA } 71862\end{array}$ & \\
\hline $\begin{array}{l}\text { 1. ISOLATED PROGRESSIVE INHERITED RETI- } \\
\text { NAL DISORDER (ORPHA 519306) }\end{array}$ & $\begin{array}{l}\text { 3. SYNDROMIC INHERITED RETINAL DISOR- } \\
\text { DER (ORPHA 519325) }\end{array}$ & $\begin{array}{l}\text { 5. CHORIORETINAL DYSTROPHIES (ORPHA } \\
519,300 \text { ) }\end{array}$ \\
\hline 1.1 Retinitis punctata albescens (ORPHA 52427) & 3.1. Alström syndrome (ORPHA 64) & 5.1. Bietti crystalline dystrophy (ORPHA 41751) \\
\hline 1.2. ARB (ORPHA 139455) & 3.2. Jalili syndrome (ORPHA 1873) & 5.2. CACD (ORPHA 75377) \\
\hline 1.3. Cone/cone-rod dystrophy (ORPHA 1872) & 3.3. Senior-Loken syndrome (ORPHA 3156) & 5.3. Choroideremia (ORPHA 180) \\
\hline $\begin{array}{l}\text { 1.4. Late-onset retinal degeneration (ORPHA } \\
67042 \text { ) }\end{array}$ & 3.4. Joubert syndrome (ORPHA 475) & $\begin{array}{l}\text { 5.4. Gyrate atrophy of choroid and retina (ORPHA } \\
414 \text { ) }\end{array}$ \\
\hline 1.5. Leber congenital amaurosis (ORPHA 65) & 3.5. Usher syndrome (ORPHA 886) & $\begin{array}{l}\text { 5.5. Helicoid peripapillary chorioretinal degenera- } \\
\text { tion (ORPHA 86813) }\end{array}$ \\
\hline $\begin{array}{l}\text { 1.6. Retinitis Pigmentosa AR } \\
\text { (ORPHA 791) }\end{array}$ & 3.6. Bardet-Biedl syndrome (ORPHA 110) & $\begin{array}{l}\text { 5.6. Pigmented paravenous retinochoroidal atro- } \\
\text { phy (ORPHA 251295) }\end{array}$ \\
\hline $\begin{array}{l}\text { 1.7. Retinitis Pigmentosa AD } \\
\text { (ORPHA 791) }\end{array}$ & $\begin{array}{l}\text { 3.7. Hallervorden-Spatz syndrome (ORPHA } \\
\text { 157850) }\end{array}$ & $\begin{array}{l}\text { 6. HEREDITARY OPTIC NEUROPATHY (ORPHA } \\
\text { 98671) }\end{array}$ \\
\hline $\begin{array}{l}\text { 1.8. Retinitis pigmentosa XL } \\
\text { (ORPHA 791) }\end{array}$ & $\begin{array}{l}\text { 3.8. Syndromic retinitis pigmentosa_-other } \\
\text { (ORPHA 519325) }\end{array}$ & $\begin{array}{l}\text { 6.1. Autosomal dominant optical atrophy (ORPHA } \\
\text { 98672) }\end{array}$ \\
\hline $\begin{array}{l}\text { 1.9. Isolated macular dystrophy (ORPHA } \\
519302 \text { ) }\end{array}$ & 3.9. Kearns-Sayre syndrome (ORPHA 480) & 6.2. Leber hereditary optic atrophy (ORPHA 104) \\
\hline 1.9.1. Sorsby fundus dystrophy (59181) & 3.10. PXE (ORPHA 758) & 6.3. Hereditary optic neuropathy—other (98671) \\
\hline 1.9.2. Stargardt disease (ORPHA 827) & 3.11. Alport Syndrome (ORPHA 63) & \\
\hline $\begin{array}{l}\text { 1.9.3. Best vitelliform macular dystrophy (ORPHA } \\
\text { 1243) }\end{array}$ & 3.12. MIDD (ORPHA 225) & $\begin{array}{l}\text { 7. OTHER RARE DISORDERS OF THE POSTE- } \\
\text { RIOR SEGMENT OF THE EYE (ORPHA 519311) }\end{array}$ \\
\hline $\begin{array}{l}\text { 1.9.4. North Carolina macular dystrophy (ORPHA } \\
\text { 75327) }\end{array}$ & $\begin{array}{l}\text { 3.13. Cuticular drusen/C3 Glomerulopathy } \\
\text { (ORPHA 329918) }\end{array}$ & 7.1. Foveal hypoplasia (ORPHA 519398) \\
\hline 1.10. Pattern dystrophy (ORPHA 63454) & $\begin{array}{l}\text { 4. INHERITED VITREOUS DYSTROPHIES } \\
\text { (ORPHA 519304) }\end{array}$ & 7.2. Coloboma (ORPHA 98942) \\
\hline $\begin{array}{l}\text { 1.10.1. Butterfly-shaped pigment dystrophy } \\
\text { (ORPHA 99001) }\end{array}$ & 4.1. X-linked retinoschisis (ORPHA 792) & 7.3. Ocular albinism (ORPHA 284804) \\
\hline $\begin{array}{l}\text { 1.10.2. MFD simulating fundus flavimaculatus } \\
\text { (ORPHA 99003) }\end{array}$ & 4.2. Stickler syndrome (ORPHA 828) & 7.4. Oculocutaneous albinism (ORPHA 55) \\
\hline $\begin{array}{l}\text { 1.10.3. Reticular dystrophy of the RPE (ORPHA } \\
\text { 99002) }\end{array}$ & 4.3. Wagner disease (ORPHA 898) & 7.5. Other \\
\hline 1.10.4. AOFVD (ORPHA 99000) & 4.4. FFEVR (OPRHA 891) & \\
\hline $\begin{array}{l}\text { 2. ISOLATED STATIONARY INHERITED RETI- } \\
\text { NAL DISORDER (ORPHA 519319) }\end{array}$ & 4.5. Goldmann-Favre syndrome/ESCS & \\
\hline 2.1. Achromatopsia (ORPHA 49382) & 4.6. ADVIRC (ORPHA 3086) & \\
\hline \multicolumn{3}{|l|}{ 2.2. CSNB (ORPHA 215) } \\
\hline \multicolumn{3}{|l|}{ 2.3. Fundus albipunctatus (ORPHA 227796) } \\
\hline $\begin{array}{l}\text { 2.4. Familial drusen/Malattia leventinese (ORPHA } \\
\text { 75376) }\end{array}$ & & \\
\hline
\end{tabular}

Bold corresponds to items (groups of diseases) that have dependences

MFD multifocal pattern dystrophy, AOFVD adult-onset foveomacular vitelliform dystrophy, CSNB congenital stationary night blindness, PXE pseudoxanthoma elasticum, MIDD maternally-inherited diabetes and deafness, FEVR familial exudative vitreoretinopathy, ADVIRC autosomal-dominant vitreoretinochoroidopathy, $C A C D$ central areolar choroidal dystrophy

a The platform allows the selection of more than one diagnosis

not something previously unseen. In fact, these diseases are also part of the Inherited Retinal Disease Classification proposed by Stone et al. [16].

We were able to design an interoperable module by reusing the retina.pt core data elements where appropriate (epidemiological data such as sex, date of birth and patient ID), whilst also incorporating bespoke data elements, sections and forms for the specific field of IRDs (Table 3). Upon selection of a particular item (clinical diagnosis, signs and symptoms, syndromic features, gene or additional diagnoses), a hyperlink is available to direct the user to the correspondent ontology webpage (ORPHA, HPO, OGG). 
Table 2 List of available IRD genes ${ }^{\mathrm{a}}$ and their respective Ontology of Genes and Genomes (OGG) and Mendelian Inheritance in Man (MIM) numbers

\begin{tabular}{|c|c|c|c|c|c|}
\hline $\mathrm{ABCA} 4$ & OGG:30000000024 & MIM:601691 & LRAT & OGG:3000009227 & MIM:604863 \\
\hline ABCC6 & OGG:30000000368 & MIM:603234 & MAK & OGG:3000004117 & MIM:154235 \\
\hline ADGRV1 & OGG:3000084059 & MIM:602851 & MERTK & OGG:3000010461 & MIM:604705 \\
\hline AIPL1 & OGG:3000023746 & MIM:604392 & MT-ND1 & OGG:3000004535 & MIM:516000 \\
\hline ALMS1 & OGG:3000007840 & MIM:606844 & MT-ND4 & OGG:3000004538 & MIM:516003 \\
\hline BBS1 & OGG:3000000582 & MIM:209901 & MT-ND4L & OGG:3000004539 & MIM:516004 \\
\hline BBS10 & OGG:3000079738 & MIM:610148 & MT-ND6 & OGG:3000004541 & MIM:516006 \\
\hline BBS12 & OGG:3000166379 & MIM:610683 & MT-TL1 & OGG:3000004567 & MIM:590050 \\
\hline BBS2 & OGG:3000000583 & MIM:606151 & MYO7A & OGG:3000004647 & MIM:276903 \\
\hline BBS3/ARL6 & OGG:3000084100 & MIM:608845 & NMNAT1 & OGG:3000064802 & MIM:608700 \\
\hline BBS4 & OGG:30000000585 & MIM:600374 & NR2E3 & OGG:3000010002 & MIM:604485 \\
\hline BBS5 & OGG:3000129880 & MIM:603650 & $N R L$ & OGG:3000004901 & MIM:162080 \\
\hline BBS7 & OGG:3000055212 & MIM:607590 & NYX & OGG:3000060506 & MIM:300278 \\
\hline BBS9 & OGG:3000027241 & MIM:607968 & OAT & OGG:3000004942 & MIM:613349 \\
\hline BEST1 & OGG:3000007439 & MIM:607854 & OPA1 & OGG:3000004976 & MIM:605290 \\
\hline C1QTNF5 & OGG:3000114902 & MIM:608752 & OPN1LW & OGG:3000005956 & MIM:300822 \\
\hline CACNA1F & OGG:30000000778 & MIM:300110 & PANK2 & OGG:3000080025 & MIM:606157 \\
\hline $\mathrm{CDH} 23$ & OGG:3000064072 & MIM:605516 & PAX6 & OGG:3000005080 & MIM:607108 \\
\hline CEP290 & OGG:3000080184 & MIM:610142 & PCARE & OGG:3000388939 & MIM:613425 \\
\hline CERKL & OGG:3000001399 & MIM:608381 & PDE6A & OGG:3000005145 & MIM:180071 \\
\hline $\mathrm{CFH}$ & OGG:3000003075 & MIM:134370 & PDE6B & OGG:3000005158 & MIM:180072 \\
\hline $\mathrm{CHM}$ & OGG:3000001121 & MIM:300390 & PDE6C & OGG:3000005146 & MIM:600827 \\
\hline CLN3 & OGG:3000001201 & MIM:607042 & PDE6G & OGG:3000005148 & MIM:180073 \\
\hline CLRN1 & OGG:3000007401 & MIM:606397 & $\mathrm{PHYH}$ & OGG:3000005264 & MIM:602026 \\
\hline CNGA3 & OGG:3000001261 & MIM:600053 & POC1B & OGG:3000282809 & MIM:614784 \\
\hline CNGB1 & OGG:3000001258 & MIM:600724 & PRCD & OGG:3000768206 & MIM:610598 \\
\hline CNGB3 & OGG:3000054714 & MIM:605080 & PROM1 & OGG:3000008842 & MIM:604365 \\
\hline CNNM4 & OGG:3000026504 & MIM:607805 & PRPF3 & OGG:3000009129 & MIM:607301 \\
\hline COL2A1 & OGG:3000001280 & MIM:120140 & PRPF31 & OGG:3000026121 & MIM:606419 \\
\hline COL4A3 & OGG:3000001285 & MIM:120070 & PRPF8 & OGG:3000010594 & MIM:607300 \\
\hline COL4A4 & OGG:3000001286 & MIM:120131 & PRPH2 (RDS) & OGG:3000005961 & MIM:179605 \\
\hline COL4A5 & OGG:3000001287 & MIM:303630 & $\mathrm{RDH} 12$ & OGG:3000145226 & MIM:608830 \\
\hline CRB1 & OGG:3000023418 & MIM:604210 & $\mathrm{RDH} 5$ & OGG:3000005959 & MIM:601617 \\
\hline CRX & OGG:3000001406 & MIM:602225 & $\mathrm{RHO}$ & OGG:3000006010 & MIM:180380 \\
\hline CYP4V2 & OGG:3000285440 & MIM:608614 & RIMS1 & OGG:3000022999 & MIM:606629 \\
\hline DHDDS & OGG:3000079947 & MIM:608172 & RLBP1 & OGG:3000006017 & MIM:180090 \\
\hline EFEMP1 & OGG:3000002202 & MIM:601548 & $\mathrm{RP} 1$ & OGG:3000006101 & MIM:3937 \\
\hline ELOVL4 & OGG:3000006785 & MIM:605512 & RP2 & OGG:3000006102 & MIM:300757 \\
\hline EYS & OGG:3000346007 & MIM:612424 & RPE65 & OGG:3000006121 & MIM:180069 \\
\hline FAM161A & OGG:3000084140 & MIM:613596 & RPGR & OGG:3000006103 & MIM:312610 \\
\hline GNAT1 & OGG:3000002779 & MIM:139330 & RPGRIP1 & OGG:3000057096 & MIM:605446 \\
\hline GNAT2 & OGG:3000002780 & MIM:139340 & RS1 & OGG:3000006247 & MIM:300839 \\
\hline GPR98 & OGG:3000084059 & MIM:602851 & SAG & OGG:3000006295 & MIM:181031 \\
\hline GRK1 & OGG:3000006011 & MIM:180381 & SEMA4A & OGG:3000064218 & MIM:607292 \\
\hline GUCA1A & OGG:3000002978 & MIM:600364 & SNRNP200 & OGG:3000023020 & MIM:601664 \\
\hline GUCA1B & OGG:3000002979 & MIM:602275 & SPATA7 & OGG:3000055812 & MIM:609868 \\
\hline GUCY2D & OGG:3000003000 & MIM:600179 & TIMP3 & OGG:3000007078 & MIM:188826 \\
\hline HGSNAT & OGG:3000138050 & MIM:610453 & TOPORS & OGG:3000010210 & MIM:609507 \\
\hline IMPDH1 (RP10) & OGG:3000003614 & MIM:146690 & TULP1 & OGG:3000007287 & MIM:602280 \\
\hline IMPG1 & OGG:3000003617 & MIM:602870 & USH1G & OGG:3000124590 & MIM:607696 \\
\hline
\end{tabular}


Table 2 (continued)

\begin{tabular}{llllll}
\hline IMPG2 & OGG:3000050939 & MIM:607056 & USH2A & OGG:3000007399 & MIM:608400 \\
IQCB1 & OGG:3000009657 & MIM:609237 & VCAN & OGG:3000001462 & MIM:118661 \\
KCNV2 & OGG:3000169522 & MIM:607604 & WDR19 & OGG:3000057728 & MIM:608151 \\
KLHL7 & OGG:3000055975 & MIM:11119 & Other & N/A & N/A \\
LCA5 & OGG:3000167691 & MIM:611408 & Inconclusive & N/A & N/A \\
\hline
\end{tabular}

a The user may select one, two or more genes in case clinically relevant variants are found in more than one gene. This list may be edited with newer additions in case other genes are found in the Portuguese population with IRDs

The family linkage section allows simple viewing of the details of affected family members that are also part of the registry. At the end of each visit, a free text area is available for comments (follow-up, imaging, prescription, etc.).

Longitudinal data is captured through specific follow-up forms. The platform allows retrospective data introduction. As the program develops, and through alignment with international data collection for IRD clinical registries, the IRD-PT core data set may be modified or extended to include additional key clinical variables.

\section{Data analysis and graphical displays}

Since the retina.pt was designed to be both a registry and a research tool, data export and analysis features are very important. A search engine that allows data filtering is available for the user to search specific anonymized data, such as the total number of affected patients or the total number of affected families with a certain diseasecausing gene, clinical diagnosis, BCVA level, etc. Furthermore, the platform offers statistical tools for simple analyses and these are also available for the IRD-PT module (Figs. 1, 2). For more sophisticated analyses, users can export their own data on excel format and analyze it as they see fit. Data are aggregated in an anonymized fashion, without identification of the individual patients.

\section{Participant characteristics}

So far, the retina.pt platform has been approved by the Human Research Ethics Committee (HREC)/Institutional Review Board (IRB) of 52 health care providers across Portugal. Each of these hospitals/clinics has established the necessary infrastructure to support rapid rollout of site and patient recruitment, data collection, and data transfer. One-hundred and thirty five users (doctors/ investigators) have applied for credentials to access the registry, and 58 of these have already included patient data. To date, there are over 1800 participants (patients) and over 30,000 consultations included in the registry. In mid 2019, the IRD-PT module was pre-launched at Centro Hospitalar e Universitário de Coimbra (CHUC), the only Portuguese health care provider ( $\mathrm{HCP})$ that is a member of the ERN-EYE, and the largest reference center for IRDs in Portugal. The idea of testing the registry in one dedicated center before its national debut was aimed to identify possible problems during data completion, test the time spent in data entry, and detect information gaps or system inaccuracies. The registry proved fully functional, fast and easy to use. As of April 1st 2020, finalized data from 537 participants were available for this preliminary analysis. Considering the Portuguese population ( 10 million inhabitants), this number corresponds to roughly $1 / 6$ of the total estimated cases of IRDs in Portugal. The distribution of the clinical diagnoses and their relative frequency among the included participants is shown in Table 4. As illustrated in Fig. 3, syndromic (14\%) and non-syndromic retinitis pigmentosa (36\%) account for $50 \%$ of the clinical diagnoses. The percentage of genetically solved and unsolved cases of syndromic and non-syndromic RP is shown in Fig. 4. Of all participants included in the IRD-PT registry to date, $57 \%$ are women and the mean age at the index visit was $39.27 \pm 19.03$ years. Average baseline BCVA was $54.36 \pm 27.22$ and final BCVA was $47.64 \pm 28.92$ ETDRS letters.

\section{Discussion}

Appropriate design, implementation and deployment of patient registries enables rapid decision making and ongoing data mining, ultimately leading to improved patient outcomes $[7,19,20]$. In the specific field of rare diseases, the use of registries increases research accessibility for individuals, while providing clinicians/ investigators with a coherent data ecosystem necessary to boost research. The IRD-PT module of retina. $p t$ will facilitate the efficient capture of accurate, longitudinal, country-wide data for IRDs. The registry will provide valuable information on disease prevalence, genomic landscape, genotype-phenotype correlations and natural history of IRDs, which is currently an unmet need in Portugal. Furthermore, the registry will facilitate patient selection for newly approved treatments or enrollment in clinical trials. The use of a webbased data storage system allows the registry to extend recruitment across multiple centers in the country. The modular design and scalable nature of the framework 


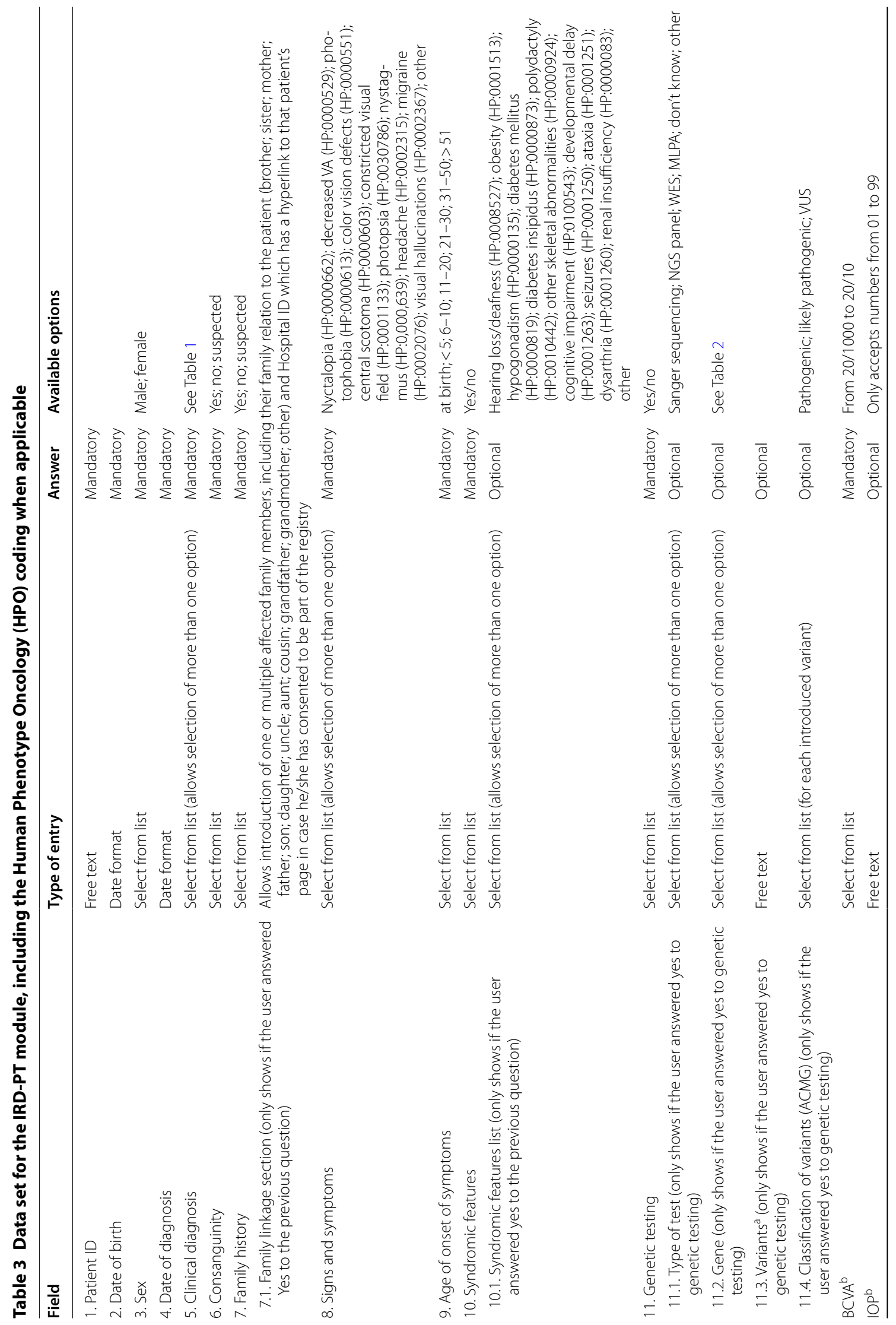




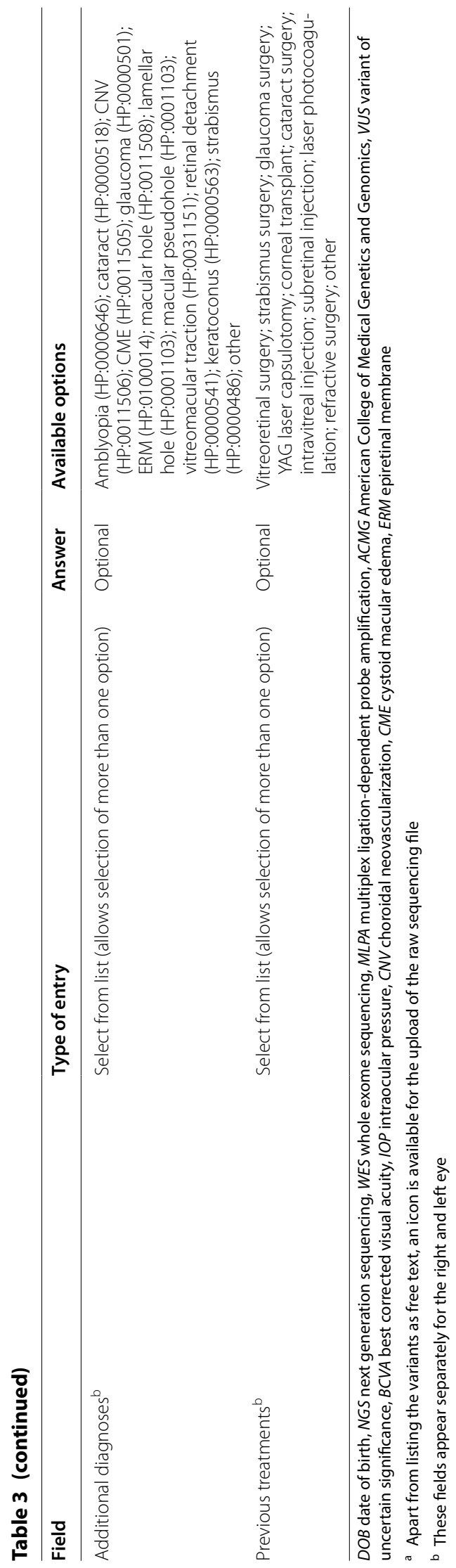




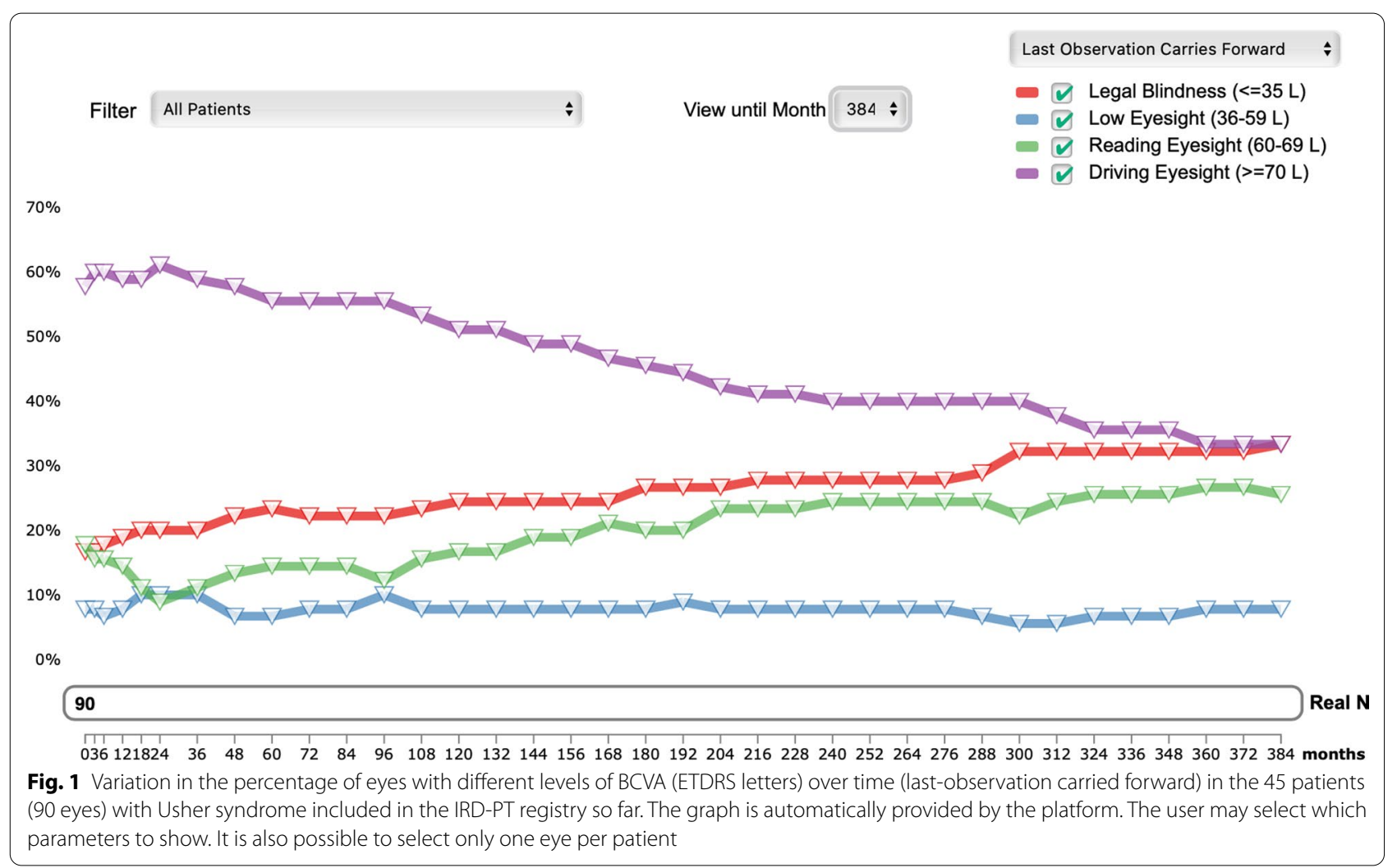

used to deploy the IRD-PT registry make it easily adaptable over time, ensuring its long-term sustainability. Furthermore, the use of domain-specific ontologies adds value to data, through an integrated knowledge base that is searchable and comparable by user and by machines $[17,21]$. In fact, by resorting to common data elements, core outcome sets, and standardized data structures, the IRD-PT module can support the exchange of data across datasets, facilitating the connection to other registries at an international level. The interoperability of this registry by means of data harmonization is a key feature pointing to its utility and scalability. Another important issue of a web-based registry is usability, i.e. the capacity of a software system to provide conditions for its users to perform the tasks satisfactorily, effectively, and efficiently. Ophthalmologists have limited time with patients during office visits, and electronic health record (EHR) use requires a substantial portion of that time, therefore affecting productivity $[22,23]$. The retina.pt registry combines a user-friendly platform and reduced load of data entry with the possibility to generate a $p d f$ document that can be saved, printed or copied to the hospital EHR system, thus eliminating the need for duplicate records. Additionally, there is also the possibility of EHR third party applications with structured information to deliver their data directly to specific subfields of the registry, thus enabling a quick fill in process. The detailed information provided on Table 3 regarding data capture for the IRD-PT may be used to modify EHR systems to allow for direct data transfer. Finally, the versatility of the platform, makes it possible to serve as electronic case report form (eCRF) for upcoming observational, natural-history or post-market authorization studies.

The IRD-PT is not exempt of limitations. An important principle in registry design is to reduce the load of data entry. This does not come without a price. By limiting the data that is considered mandatory to a minimum, there may be incomplete information/missing data for some included subjects concerning unanswered non-mandatory fields. Another limitation is that grading systems/ levels for the symptoms or degree of impairment are not available. The fact that symptoms are simply marked as present/not present prevents a precise characterization of these symptoms during the disease course. Finally, since each user is responsible for its own data entry, we cannot be sure about the accuracy of its contents. This may be particularly problematic when a case is considered molecularly solved or unsolved. Misinterpretation of the genetic findings is not uncommon, which may lead to selection bias regarding the number of molecularly solved/unsolved cases. 


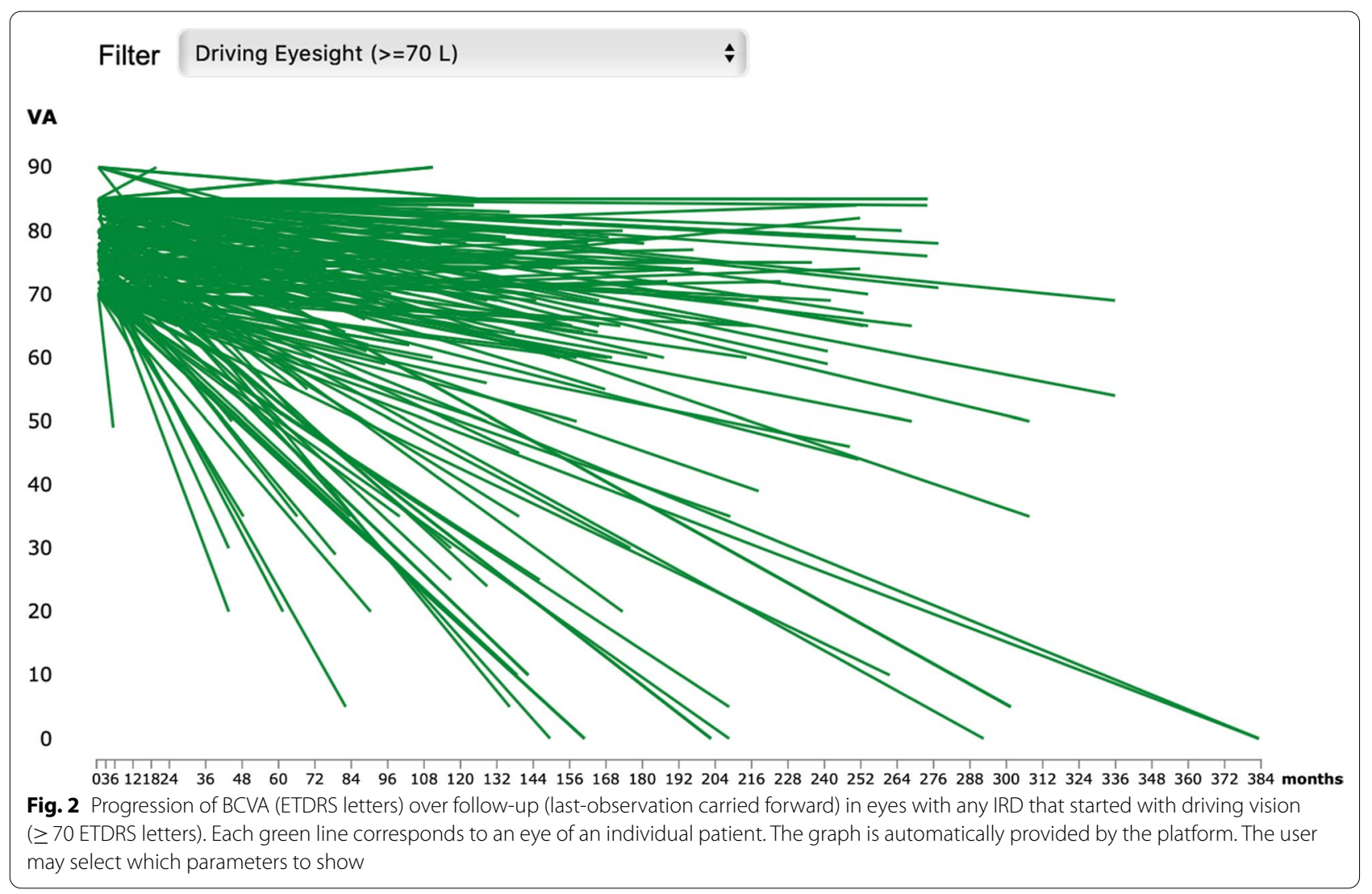

\section{Conclusions}

We have described here the principles behind the design, development and deployment of a web-based software tool that forms the basis of a nation-wide registry for IRDs. The pre-launch of the IRD-PT module in the largest Portuguese referral center for IRDs (CHUC), allowed to test the functionalities of the registry and enroll the first 537 IRD patients, roughly $1 / 6$ of the total estimated cases of IRDs in Portugal. Now that the module is fully working, recruitment will be extended to other Portuguese hospitals. Judging from the enthusiasm and adherence observed with the launch of the retina.pt platform, we believe that the IRD-PT registry will be rapidly adopted by the Portuguese ophthalmologists managing IRD patients. Our hope is to generate important knowledge and collect high-quality data on the epidemiology, genomic landscape, genotype-phenotype correlations and natural history of IRDs in Portugal. This will both boost and excel clinical research in the field of IRDs in our country, while facilitating patient access to clinical trials or new therapies.

\section{Methods \\ Registry design}

The IRD-PT is a clinical/genetic research registry. Its main goal is to create a national, web-based registry of IRDs in Portugal that allows to study their prevalence, genomic profile, genotype-phenotype correlations and natural history. Also, the registry may assist in the recruitment of participants for new treatments/clinical trials, and provide support for the establishment of disease-specific standards and care. The IRD-PT registry is included in the retina.pt platform (https://www. retina.com.pt), which was developed by the Portuguese Retina Study Group (GER, www.ger-portugal.com). The retina.pt registry deployed in 2017 to fulfil a vital component on patient-centered care for retinal diseases. It collects data on individuals diagnosed with retinal diseases, from several sites across Portugal, with over 1800 participants and over 30,000 consultations to date. The IRD-PT is a module interacting with the retina.pt core system. The core system provides a range of basic functions used for patient data management, while the 
Table 4 Distribution of the clinical IRD diagnoses and their relative frequency among the 537 subjects included in the IRD-PT registry

\begin{tabular}{|c|c|c|}
\hline Clinical diagnosis & $\mathbf{n}$ & $\begin{array}{l}\text { Relative } \\
\text { frequency } \\
(\%)\end{array}$ \\
\hline Non-syndromic RP & 192 & 35.75 \\
\hline Syndromic RP & 74 & 13.78 \\
\hline Cone/cone-rod dystrophy & 62 & 11.55 \\
\hline Stargardt disease & 27 & 5.03 \\
\hline PXE & 21 & 3.91 \\
\hline Pattern dystrophy & 20 & 3.72 \\
\hline ADOA (Kjer) & 14 & 2.61 \\
\hline Leber congenital amaurosis & 12 & 2.23 \\
\hline Best vitelliform macular dystrophy & 12 & 2.23 \\
\hline Foveal hypoplasia & 11 & 2.05 \\
\hline X-linked retinoschisis & 10 & 1.86 \\
\hline PPRCA & 7 & 1.30 \\
\hline Achromatopsia & 6 & 1.12 \\
\hline Ocular/oculocutaneous albinism & 6 & 1.12 \\
\hline CACD & 6 & 1.12 \\
\hline Choroideremia & 6 & 1.12 \\
\hline CSNB & 5 & 0.93 \\
\hline Coloboma & 5 & 0.93 \\
\hline ARB & 4 & 0.74 \\
\hline Bietti crystalline dystrophy & 4 & 0.74 \\
\hline Fundus albipunctatus & 4 & 0.74 \\
\hline MIDD & 4 & 0.74 \\
\hline Gyrate atrophy of choroid and retina & 3 & 0.56 \\
\hline Goldmann-Favre syndrome/ESCS & 3 & 0.56 \\
\hline Stickler/Wagner syndrome & 3 & 0.56 \\
\hline Cuticular drusen/C3 glomerulopathy & 3 & 0.56 \\
\hline LORD & 3 & 0.56 \\
\hline LHON & 3 & 0.56 \\
\hline ADVIRC & 2 & 0.37 \\
\hline Retinitis punctata albescens & 2 & 0.37 \\
\hline Alport syndrome & 2 & 0.37 \\
\hline NCMD & 1 & 0.19 \\
\hline
\end{tabular}

$R P$ retinitis pigmentosa, $P X E$ pseudoxanthoma elasticum, $A D O A$ autosomal dominant optic atrophy, $P P R C A$ pigmented paravenous retinochoroidal atrophy, $C A C D$ central areolar choroidal dystrophy, CSNB congenital stationary night blindness, $A R B$ autosomal recessive bestrophinopathy, MIDD maternally inherited diabetes and deafness, ESCS enhanced S-cone syndrome, LORD lateonset retinal degeneration, $L H O N$ leber hereditary optic neuropathy, ADVIRC autosomal dominant vitreoretinochoroidopathy, NCMD North Carolina macular dystrophy

IRD-PT module provides the user with the functionality to capture data for the specific purpose of IRDs.

\section{Recruitment and informed consent}

Both pediatric and adult patients with a genetic and/or clinical diagnosis of IRD living in Portugal and attending
Ophthalmology clinics around the country are invited to participate. Participation in the registry is voluntary. Before enrollment, the participant (patient) or their legally authorized representative must provide informed consent for the collection, storage, and use of their personal health data. No costs or compensations are involved for participants or their family members as the data collected in the IRD-PT module refers to information routinely collected by the responsible physician. All included subjects are allowed to withdraw their consent at any time, without providing a reason. This does not impact their regular follow-up at the clinic.

\section{Ethics and regulations}

The registry meets the necessary requirements for compliance with the General Data Protection Regulation (GDPR) of the European Union and all approvals were obtained prior to recruiting patients for the registry. Formal review and approval was obtained from the Portuguese Data Protection Authority (Comissão Nacional de Proteção de Dados-CNPD), HREC of Centro Hospitalar e Universitário de Coimbra (CHUC) and IRB of the Faculty of Medicine of the University of Coimbra (FMUC). All these independent entities ensured that the study protocol, governance, protections, and methods were ethical and appropriate. Furthermore, each participating core center needs to obtain approval from the respective Ethics Committee. Documentation of approval from each center is copied to the central governing office to ensure currency of approval is maintained.

All investigators (users) are mandated to sign the Investigator Declaration Form before obtaining credentials to use the registry. Both the project investigators and their institutions permit project-related monitoring, audits, and regulatory inspections, providing direct access to source data/documents. This may include, but is not limited to, review by HREC and institutional governance review bodies.

\section{Data protection}

Proper handling of ethical, legal, social, and privacy issues must be a foundational component of the design, implementation, and long-term sustainability of a patient registry [7]. As part of the retina.pt, the IRD-PT module was designed to provide maximum data security and patient anonymity. Several well-defined procedures were put in place to protect individual patient data within the registry study. Data security, integrity, and availability is monitored and regulated.

All data transmissions between the user and the server are encrypted using 128-bit encryption (Secure Sockets Layer). The data are stored and backed up on secure servers at Portugal Telecom-Altice, TEAR 3 certified 


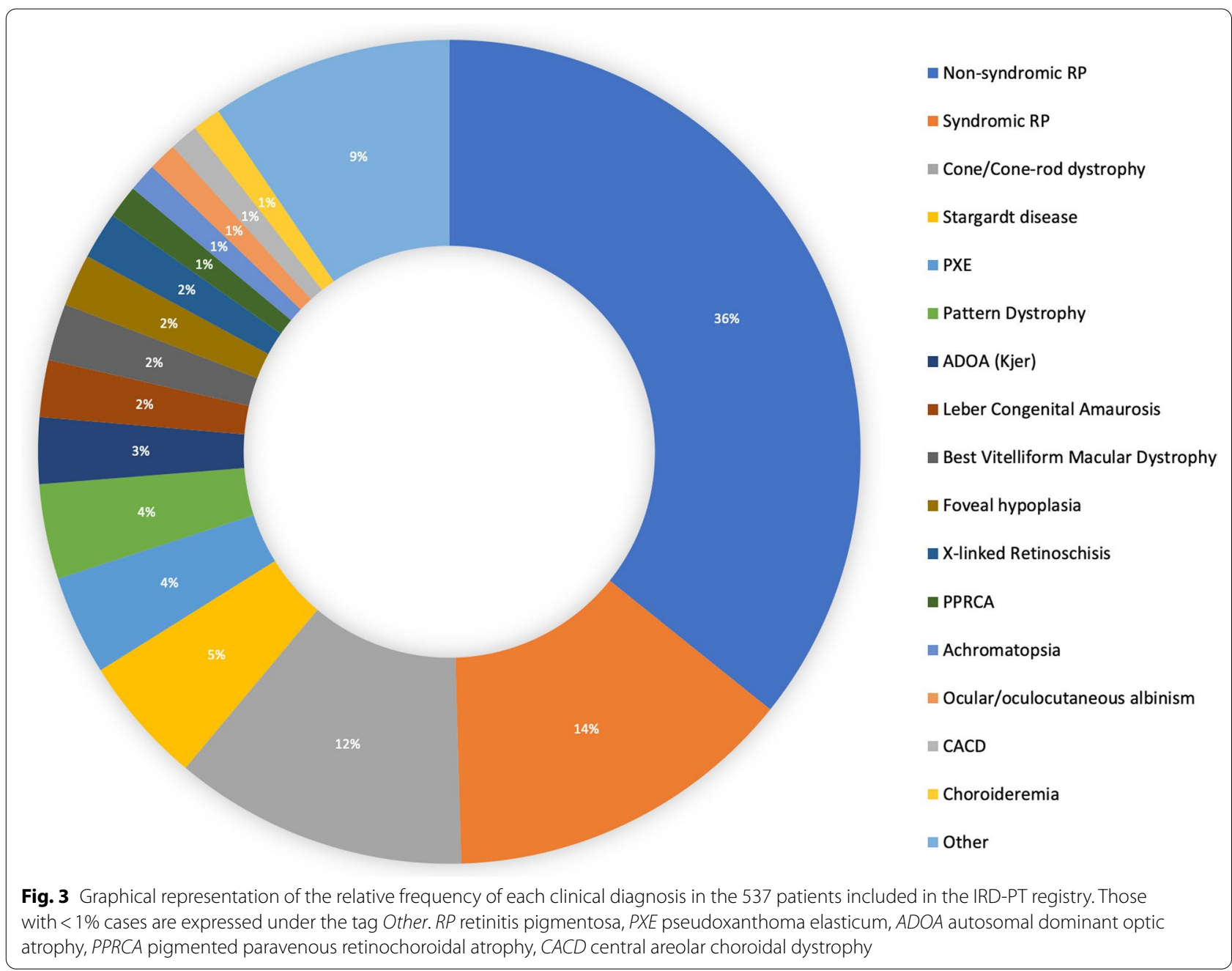

Datacenter. Anonymity of users is also closely guarded. Individual users can only see their own data. However, users may find other centers with included data on a specific disease and ask for research collaborations within the platform. Users can withdraw their data from the registry at any time, without providing a reason.

\section{Registry interface}

Drop-down menus, pop-up explanatory notes, and tabto-jump ensures rapid and user friendly data entry. Furthermore, retina.pt is a web-based application that is able to run on different server operating systems. Any device with Internet access and a recent browser can be used to interact with the application. Additional software on the user's terminal is not required. When all mandatory fields have been filled, the User can "Finalize" the visit by pressing "Save". The system has been designed in such a way that it will not allow a visit to be finalized unless all the mandatory fields have been filled and all numerical data fall within prespecified ranges. Additionally, the platform allows data to be automatically filled in by third party EHR applications with identically structured information, or the possibility of the user to generate a $p d f$ document that can be printed/copied to the hospital EHR system. Moreover, storage and retrieval of clinical images is possible in the patient-specific page.

\section{Data quality}

High quality data of rare diseases registries is considered to be one of the most important elements in the establishment and maintenance of a registry [20]. Quality assurance includes quality improvement activities such as medical, clinical, and record audit and observational studies, to which the ethical principles of research apply.

\section{Interoperability}

Upon the development of the retina.pt platform, interoperability was a key issue. First, the registry has two available languages to choose from: Portuguese and English. Second, the age-related macular degeneration (AMD) 


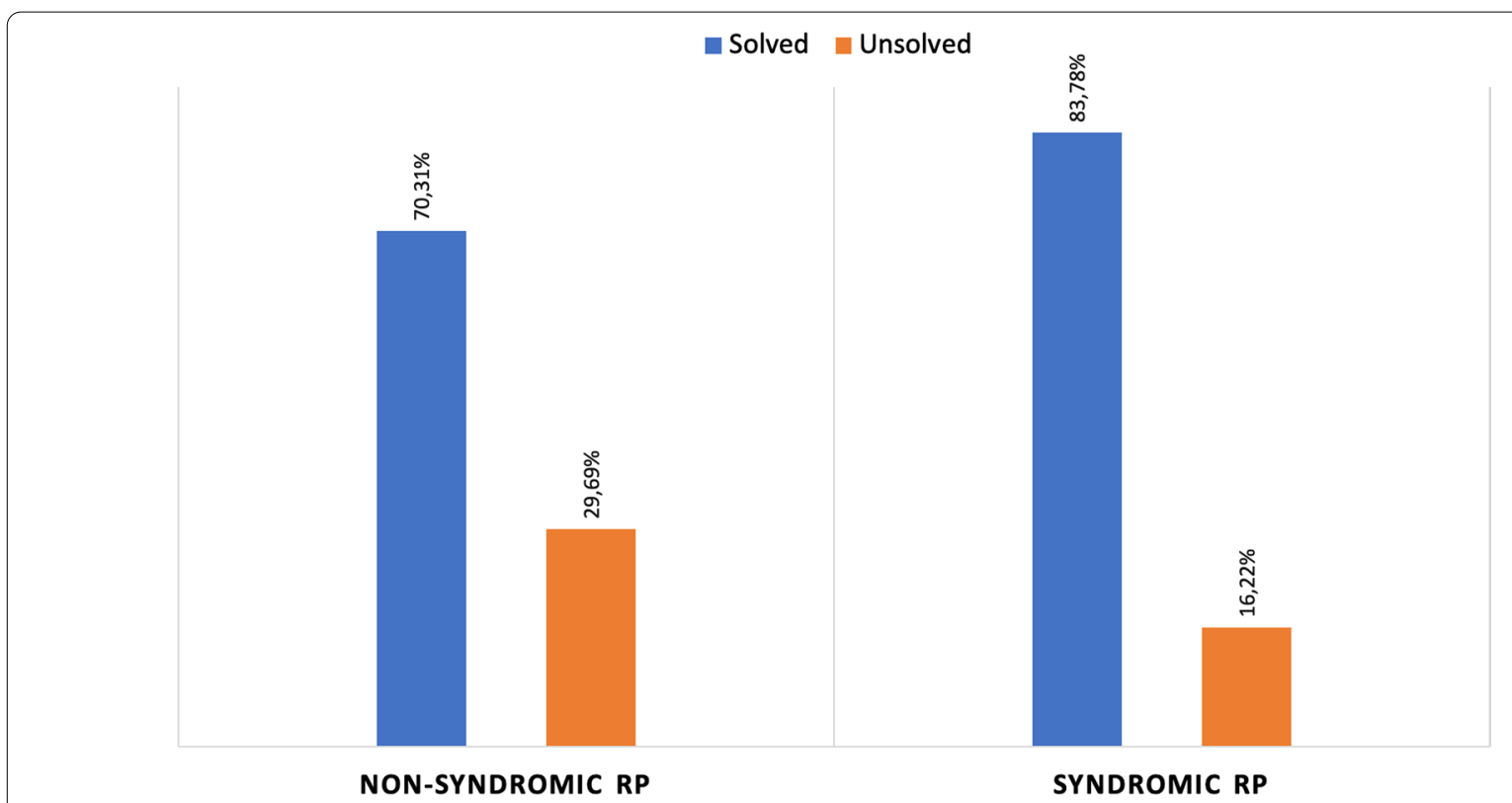

Fig. 4 Graphical representation of the percentage of genetically solved and genetically unsolved cases of syndromic and non-syndromic retinitis pigmentosa in our cohort

module of retina.pt is already linked to the Fight Retinal Blindness! (FRB!) Project registry [2] and efforts are in place to connect it to the International Consortium for Health Outcomes Measurement (ICHOM) AMD registry. Third, the platform is serving as the eCRF for an upcoming post-market authorization clinical trial. Rare diseases are a prime example of a research area that can strongly profit from coordination on a European and international scale. To allow interoperability of the IRDPT module with other IRD registries across the world, all the diseases are coded accordingly to ICD9, ICD10, ICD11, and ORDO (ORPHA codes) numbers. Furthermore, the genes are coded according to the OGG and MIM, and patient signs and symptoms are coded according to HPO. This is in accordance with the eye-specific dataset of the Clinical Patient Management System (CPMS) of the ERN-EYE [17]. Notably, ORDO, HPO, OGG and MIM are open-access, interoperable, community-driven, available in multiple languages and regularly updated.

\section{Acknowledgements}

The authors would like to acknowledge Sara Costa, Paulo Castro and Carlos Castro, members of Inovasis, for the critical IT support during the development and deployment of the retina.pt platform in general and the IRD-PT module in particular. The authors would also like to acknowledge Novartis Portugal and the Portuguese Society of Ophthalmology for the funding that made the development of the IRD-PT module possible.

\section{Authors' contributions}

JPM conceptualized, designed and drafted the manuscript. JH and RS conceptualized and substantively revised the manuscript. ALC, JS and JNM substantively revised the manuscript. All authors have read and approved the submitted version, and have agreed both to be personally accountable for the author's own contributions and to ensure that questions related to the accuracy or integrity of any part of the work, even ones in which the author was not personally involved, are appropriately investigated, resolved, and the resolution documented in the literature. All authors read and approved the final manuscript.

\section{Funding}

The retina.pt platform receives annual funding from industry stakeholders (Novartis, Bayer, Allergan and Alimera). This is used for data management activities, IT support, layout improvements and legal support. None of the aforementioned companies had any interference on the design or development of the registry, nor have any type of proprietary interest in the generated data. The IRD-PT module received specific funding for its development and implementation, namely for IT support, data management activities, design and layout. This came as a grant from Novartis Portugal and the Portuguese Society of Ophthalmology. Neither entity had, has or will have any interference on the collection, analysis, and/or interpretation of data, nor have any type of proprietary interest in the generated data.

\section{Availability of data and materials}

The datasets used and/or analyzed during the current study are available from the corresponding author on reasonable request.

\section{Ethics approval and consent to participate}

Formal review and approval was obtained from the Portuguese Data Protection Authority (Comissão Nacional de Proteção de Dados-CNPD), Human Research Ethics Committee (HREC) of Centro Hospitalar e Universitário de Coimbra (CHUC) and Institutional Review Board (IRB) of the Faculty of Medicine of the University of Coimbra (FMUC). Additionally, each participating core health care provider needs to obtain approval from the respective Ethics Committee. Documentation of approval from each center is copied to the central governing office to ensure currency of approval is maintained.

\section{Consent for publication}

Not applicable.

\section{Competing interests}

The authors declare that they have no competing interests in regard to this manuscript. 


\begin{abstract}
Author details
${ }^{1}$ Ophthalmology Unit, Centro de Responsabilidade Integrado em Oftalmologia (CRIO), Centro Hospitalar e Universitário de Coimbra (CHUC), Praceta Prof. Mota Pinto, 3000-075 Coimbra, Portugal. ${ }^{2}$ University Clinic of Ophthalmology, Faculty of Medicine, University of Coimbra (FMUC), Coimbra, Portugal. ${ }^{3}$ Clinical Academic Center of Coimbra (CACC), Coimbra, Portugal. ${ }^{4}$ Medical Genetics Unit, Centro Hospitalar e Universitário de Coimbra (CHUC), Coimbra, Portugal. ${ }^{5}$ University Clinic of Medical Genetics, Faculty of Medicine, University of Coimbra (FMUC), Coimbra, Portugal. ${ }^{6}$ Instituto de Oftalmologia Dr. Gama Pinto (IOGP), Lisbon, Portugal. ${ }^{7}$ University Clinic of Pediatrics, Faculty of Medicine, University of Coimbra (FMUC), Coimbra, Portugal.
\end{abstract}

Received: 15 May 2020 Accepted: 15 October 2020

Published online: 27 October 2020

\section{References}

1. Gliklich RE, Dreyer NA, Leavy MB. Quintiles outcome (Firm), United States. Agency for Healthcare Research and Quality, Effective Health Care Program (U.S.): Registries for evaluating patient outcomes: a user's guide. In: AHRQ publication no 13(14)-EHC111, 3rd edn. Agency for Healthcare Research and Quality, Rockville, MD; 2014: 1 online resource (2 PDF files (2 volumes)).

2. Gillies MC, Walton R, Liong J, Arnold JJ, McAllister I, Morlet N, Hunyor A, Guymer R, Keeffe J, Essex R, et al. Efficient capture of high-quality data on outcomes of treatment for macular diseases: the fight retinal blindness! Project. Retina. 2014;34(1):188-95.

3. Chiang MF, Sommer A, Rich WL, Lum F, Parke DW. 2nd: The 2016 American Academy of Ophthalmology IRIS((R)) Registry (Intelligent Research in Sight) database: characteristics and methods. Ophthalmology. 2018;125(8):1143-8.

4. Lundstrom M, Manning S, Barry P, Stenevi U, Henry Y, Rosen P. The European registry of quality outcomes for cataract and refractive surgery (EUREQUO): a database study of trends in volumes, surgical techniques and outcomes of refractive surgery. Eye Vis (Lond). 2015;2:8.

5. Lum F, Schachat AP, Jampel HD. The development and demise of a cataract surgery database. Jt Comm J Qual Improv. 2002;28(3):108-14.

6. Tan JCK, Ferdi AC, Gillies MC, Watson SL. Clinical registries in ophthalmology. Ophthalmology. 2019;126(5):655-62.

7. Boulanger V, Schlemmer M, Rossov S, Seebald A, Gavin P. Establishing patient registries for rare diseases: rationale and challenges. Pharmaceut Med. 2020;34(3):185-190. https://doi.org/10.1007/s40290-020-00332-1.

8. Broadgate S, Yu J, Downes SM, Halford S. Unravelling the genetics of inherited retinal dystrophies: past, present and future. Prog Retin Eye Res. 2017:59:53-96.

9. Sharon D, Ben-Yosef T, Goldenberg-Cohen N, Pras E, Gradstein L, Soudry S, Mezer E, Zur D, Abbasi AH, Zeitz C, et al. A nationwide genetic analysis of inherited retinal diseases in Israel as assessed by the Israeli inherited retinal disease consortium (IIRDC). Hum Mutat. 2020;41(1):140-9.

10. Gao FJ, Li JK, Chen H, Hu FY, Zhang SH, Qi YH, Xu P, Wang DD, Wang LS, Chang Q, et al. Genetic and clinical findings in a large cohort of
Chinese patients with suspected retinitis pigmentosa. Ophthalmology. 2019;126:1549-56.

11. Holtan JP, Selmer KK, Heimdal KR, Bragadottir R. Inherited retinal disease in Norway - a characterization of current clinical and genetic knowledge. Acta Ophthalmol. 2020;98(3):286-95.

12. Haer-Wigman L, van Zelst-Stams WA, Pfundt R, van den Born LI, Klaver CC, Verheij JB, Hoyng CB, Breuning MH, Boon CJ, Kievit AJ, et al. Diagnostic exome sequencing in 266 Dutch patients with visual impairment. Eur J Hum Genet. 2017;25(5):591-9.

13. Patel N, Alkuraya $H$, Alzahrani SS, Nowailaty SR, Seidahmed MZ, Alhemidan A, Ben-Omran T, Ghazi NG, Al-Aqeel A, Al-Owain M, et al. Mutations in known disease genes account for the majority of autosomal recessive retinal dystrophies. Clin Genet. 2018;94(6):554-63.

14. Kim MS, Joo K, Seong MW, Kim MJ, Park KH, Park SS, Woo SJ. Genetic mutation profiles in Korean patients with inherited retinal diseases. J Korean Med Sci. 2019;34(21):e161.

15. Motta FL, Martin RP, Filippelli-Silva R, Salles MV, Sallum JMF. Relative frequency of inherited retinal dystrophies in Brazil. Sci Rep. 2018;8(1):15939.

16. Stone EM, Andorf JL, Whitmore SS, DeLuca AP, Giacalone JC, Streb LM, Braun TA, Mullins RF, Scheetz TE, Sheffield VC, et al. Clinically focused molecular investigation of 1000 consecutive families with inherited retinal disease. Ophthalmology. 2017;124(9):1314-31.

17. Sergouniotis PI, Maxime E, Leroux D, Olry A, Thompson R, Rath A, Robinson PN, Dollfus H. Group E-EOS: an ontological foundation for ocular phenotypes and rare eye diseases. Orphanet J Rare Dis. 2019;14(1):8.

18. Wilkinson MD, Dumontier M, Aalbersberg IJ, Appleton G, Axton M, Baak A, Blomberg N, Boiten JW, da Silva Santos LB, Bourne PE, et al. The FAIR Guiding Principles for scientific data management and stewardship. Sci Data. 2016;3:160018.

19. Bellgard MI, Render L, Radochonski M, Hunter A. Second generation registry framework. Source Code Biol Med. 2014:9:14.

20. Kodra Y, de la Paz MP, Coi A, Santoro M, Bianchi F, Ahmed F, Rubinstein YR, Weinbach J, Taruscio D. Data quality in rare diseases registries. Adv Exp Med Biol. 2017;1031:149-64.

21. Sernadela P, Gonzalez-Castro L, Carta C, van der Horst E, Lopes P, Kaliyaperumal R, Thompson M, Thompson R, Queralt-Rosinach N, Lopez E, et al. Linked registries: connecting rare diseases patient registries through a semantic web layer. Biomed Res Int. 2017;2017:8327980.

22. Read-Brown S, Hribar MR, Reznick LG, Lombardi LH, Parikh M, Chamberlain WD, Bailey ST, Wallace JB, Yackel TR, Chiang MF. Time requirements for electronic health record use in an academic ophthalmology center. JAMA Ophthalmol. 2017:135(11):1250-7.

23. Sinsky C, Colligan L, Li L, Prgomet M, Reynolds S, Goeders L, Westbrook J, Tutty M, Blike G. Allocation of physician time in ambulatory practice: a time and motion study in 4 specialties. Ann Intern Med. 2016;165(11):753-60

\section{Publisher's Note}

Springer Nature remains neutral with regard to jurisdictional claims in published maps and institutional affiliations.

\footnotetext{
Ready to submit your research? Choose BMC and benefit from:

- fast, convenient online submission

- thorough peer review by experienced researchers in your field

- rapid publication on acceptance

- support for research data, including large and complex data types

- gold Open Access which fosters wider collaboration and increased citations

- maximum visibility for your research: over $100 \mathrm{M}$ website views per year
}

At BMC, research is always in progress.

Learn more biomedcentral.com/submissions 